\title{
Detecting changes in sediment overburden using distributed temperature sensing: an experimental and numerical study
}

\author{
Yi Rui $^{1} \cdot$ Robert Hird ${ }^{2}\left(\mathbb{D} \cdot\right.$ Mei Yin $^{2} \cdot$ Kenichi Soga ${ }^{3}$
}

Received: 16 January 2018 / Accepted: 9 August 2018 / Published online: 21 August 2018

(c) The Author(s) 2018

\begin{abstract}
Fibre optic cables can be used as sensors to monitor temperature changes through the analysis of back scattered light. This can be linked to changes in the ambient conditions surrounding the fibre optic cable. Active distributed temperature sensing relies on an external heat source relative to the fibre optic cable to measure the properties of, and changes in, the surrounding medium. An experiment was conducted using distributed temperature sensing technology to monitor changes in sediment overburden for the purpose of determining whether scour could be measured above buried power cables containing fibre optic cables. Fibre optic cables were buried in a channel containing saturated sand and water with an external heat source. The depth of overburden sediment above the fibre optic cables was reduced, whilst the associated temperature response along the fibre optic cable was monitored. The data was matched to a finite element model so that the heat transfer taking place could be simulated and then the thermal conductivity of the soil modified to observe the potential changes in heat detected by the fibre optic cables. This paper explains the characteristics of heat transfer from an active heat source to the surrounding soil medium providing a means to translate the temperature measurement to the associated overburden thickness and to model the same response in different materials.
\end{abstract}

Keywords Distributed temperature sensing $\cdot$ Buried power cables $\cdot$ Seabed scour $\cdot$ Optic fibre sensor $\cdot$ Numerical modelling

$\begin{array}{ll}\text { Abbreviations } \\ \text { BOTDA } & \text { Brillouin optical time domain analysis } \\ \text { DTS } & \text { Distributed temperature sensing } \\ \text { FE } & \text { Finite element } \\ \text { OFS } & \text { Optical fibre sensor } \\ \mathrm{c} & \text { Heat capacity } \\ \mathrm{n} & \text { Porosity } \\ \mathrm{T} & \text { Temperature } \\ \Delta \mathrm{T} & \text { Change in relation to a reference temperature } \\ \mathrm{k} & \text { Thermal conductivity } \\ \rho & \text { Material mass density }\end{array}$

Robert Hird

rh500@cantab.net

1 Centre for Smart Infrastructure \& Construction, Department of Engineering, University of Cambridge, Cambridge, UK

2 Schofield Centre, Department of Engineering, University of Cambridge, Cambridge, UK

3 Department of Civil and Environmental Engineering, University of California, Berkeley, USA

\section{Introduction}

Sediment scour is an important concern in river and marine environments especially in relation to buried assets. Sediment mobility leading to changes in bathymetry can be detected by conventional geophysical techniques but is costly and effectiveness is largely limited to prevailing water conditions such as currents, waves and swell. Fibre optics as sensors offer an alternative remote method to measure scour though studies have largely focused on single point measurement (see Lin et al. 2005).

Fibre optic cables, as an optical fibre sensor (OFS), can be used to monitor changes in temperature through analysis of backscattered light. Backscattered light is composed of three main spectral components: Rayleigh, Raman and Brillouin, of which Raman and Brillouin are currently used to report spatial variation of temperature and/or strain along the optical fibre. Raman spectra differ from Brillouin spectra by having a fixed frequency but variable intensity. In comparison, Brillouin interaction exhibits a frequency shift through the scattering process; that is, the correlation of the frequency shift is linearly dependant on the refractive properties of the 
optical fibre and thus the strain and temperature changes within.

Distributed temperature sensing (DTS) systems can be used to measure spatial $\left( \pm 0.5 \mathrm{~m}, 0.3{ }^{\circ} \mathrm{C}\right)$ and temporal $(<5 \mathrm{~min})$ variability in the subsurface at a high resolution along an OFS over tens of kilometres in length. Two forms of measurement are currently recognised: active and passive sensing. Passive sensing can be used to monitor the ambient temperature of the subsurface when an OFS is buried or placed on top of the seabed. Active sensing relies on an external heat source which may vary depending on changes to internal and external properties of the surrounding medium. An example would be power cables where electrical resistance within the conductor gives rise to internal heat. DTS systems have been successfully demonstrated in a variety of applications, such as monitoring terrestrial pipelines (Inaudi and Glisic 2010), to determine ground source heat pump efficiency (Bourne-Webb et al. 2009), understand ecological impacts of rhododendron canopy in woodland environments (Krause et al. 2012), to differentiate between present and fresh bentonite suspensions in diaphragm wall construction (Spruit et al. 2017) and in hydrological temperature-depth profiling (Arnon et al. 2014). Indirect monitoring has also been attempted to measure soil moisture content (Steele-Dunne et al. 2010), to control acid injection into rock reservoirs (Grayson et al. 2015), to assess the structural integrity of concrete (Grosso et al. 2001; Lau 2003), and to measure salinity variability (Arnon et al. 2014).

The use of DTS to detect changes in soil and/or sediment thickness appears to be a new area of research where documented evidence is rare, especially for active DTS. Passive DTS monitoring has been used to detect erosion of a canal dyke using fibre optic cable woven into geotextile (Artieres et al. 2012), monitor sedimentation and scour in river beds (Sebok et al. 2015, 2017) and detect bedload transport and disentrainment of coarse grained soils in rivers during flooding (Bray and Dunne 2017). Zhao et al. (2012) studied the effect of scour around pipelines using active DTS. This paper introduces another active DTS method using change in soil temperature to monitor overburden thickness for use in remote seabed scour measurement.

To determine whether seabed scour can be detected in real-time above a buried power cable containing fibre optic sensors a controlled experiment using Brillouin optical time domain analysis (BOTDA) is presented in this paper. It follows on from the experimental work by Ouyang et al. (2017) by introducing a numerical code specific to heat transfer applications. The computed results are then compared to the experimental data for the same boundary conditions. An intrinsic soil property is then changed and the heat transfer is assessed with the numerical model thus potentially expanding the use of the fibre optic active DTS for wider geophysical applications.
This paper is set out in three main parts each containing separate results and discussions:

Part 1 Experiment details and evaluation: describes the setup of the experimental model and the fibre optic sensors, verification of baseline temperature under steady state conditions, method to remove sediment overburden and corresponding OFS measurement and analysis;

Part 2 Numerical model and validation: introduces the numerical model and how it is applied to simulate the physical model;

Part 3 Parametric study: discusses the effect on temperature by changing soil thermal conductivity.

\section{Part 1. Experimental details and evaluation}

\section{Experiment setup}

A concrete channel containing sand with a covering of water formed the basis of the physical model used in this study. A heat tape was embedded in the sand together with an OFS, where the heat tape mimicked the power cable in generating heat. Sediment cover was manually reduced and the temperature change was monitored, demonstrating the sensitivity of the monitoring system to measure real time changes in overburden thickness. A numerical model was then created and validated with the experimental data prior to simulating a change in soil properties using parametric analysis, which is discussed in the latter part of this paper. The test set-up consisted of ten $1 \mathrm{~m}$ long sections of a concrete U-channel (referred here as just 'channel') that had been locked together with a silicone sealant placed between each joint. The dimensions of the channel cross section are presented in Fig. 1a.

A vertical wall comprising $12 \mathrm{~mm}$ thick waterproofed plywood was glued and then clamped at each end of the channel using corner clamps at the top and a gravity block at the base. At $50 \mathrm{~mm}$ above the base of the channel, a $18 \mathrm{~mm}$ hole was drilled to accommodate the heating tape. The selfregulating heating tape was supplied by Heat Trace, UK as $75 \mathrm{FSS} 2-\mathrm{A}$ rated at $75 \mathrm{~W}$ per meter. This value is in the reasonable range of energy loss of submarine power cable according to the numerical modelling by Pilgrim et al. (2013). Self-regulating heat tapes are cables whose local resistance increases when the temperature in that location rises beyond target, thereby reducing the local heat output while the remainder of the cable generates heat as before. The aim was to supply heat only where it was needed to maintain the source temperature.

The OFS were encased in a $220 \mathrm{~mm}$ thick layer of uniformly graded sand that had been placed in layers whilst 


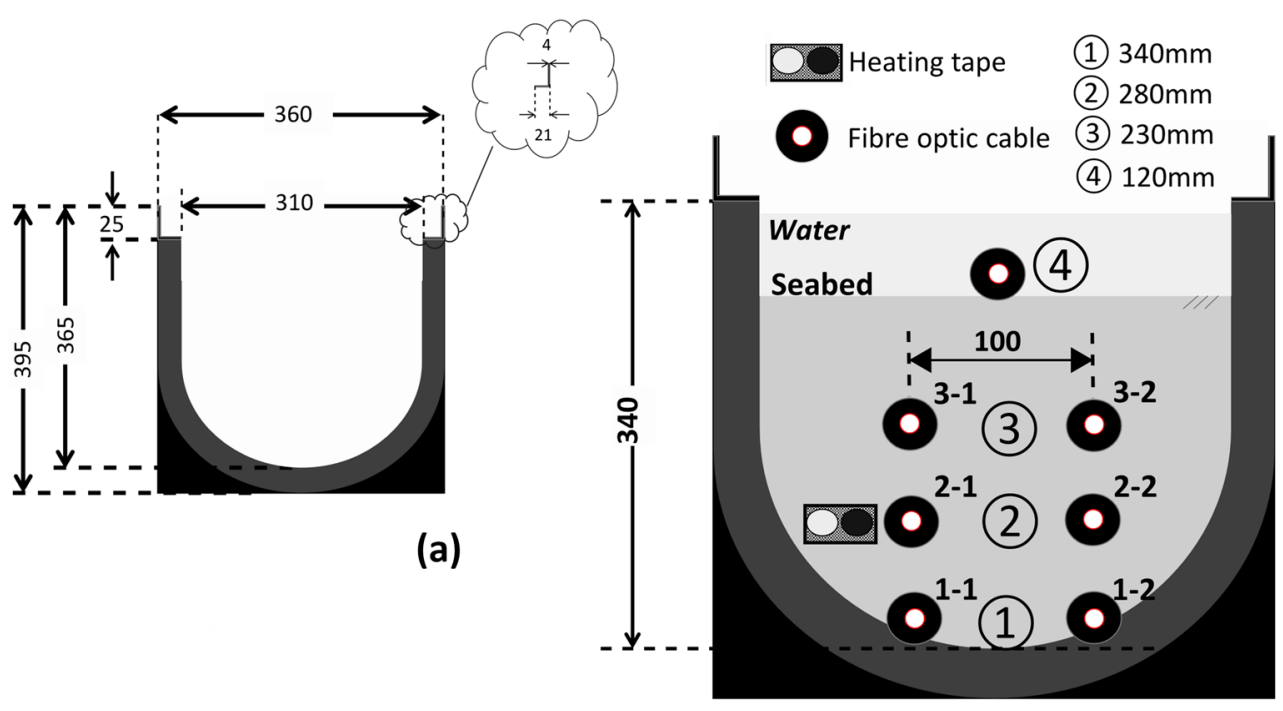

(b)

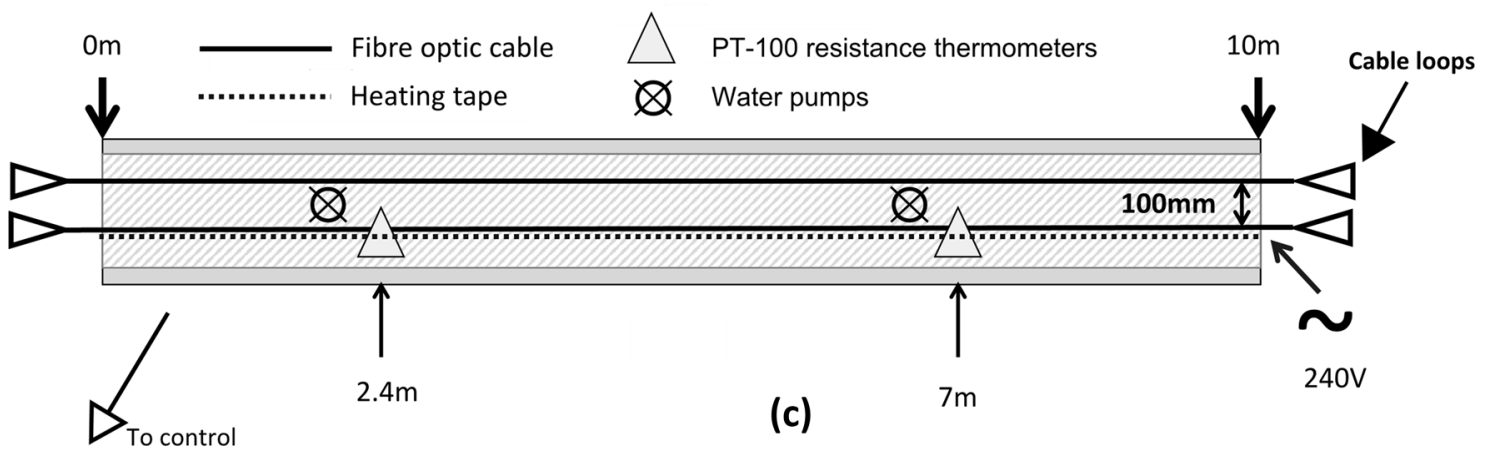

Fig. 1 Sketch of the experimental setup. a Dimensions of the channel; $\mathbf{b}$ placement of heat tape and fibre optical cables within the sand; $\mathbf{c}$ plan view showing position of PT-100 thermometers

submerged in water to remove air and achieve a uniform density. A 100 m long OFS (Mayflex Excel OS2 4C 9/125), was placed in the $10 \mathrm{~m}$ long channel with $4 \mathrm{~m}$ loops exposed outside the channel at each end. The OFS was of a loose tube construction with single mode fibres protected with hydrophobic gel to prevent strain transfer and was specifically chosen to monitor temperature only. Similar methods were adopted by Rui et al. (2017). The OFS was doubled back along the channel at the same elevation or placed at a different elevation. The significant length of the exposed loops was necessary to contrast against the buried OFS so that each fibre optic cable section could be identified during analysis. The first lengths of OFS were fixed to the base of the channel using duct tape. Subsequent lengths of OFS at higher elevations were temporarily held in place with weights to prevent buoyancy whilst sand was laid on top. The OFS positions were identified as 1,2 and 3 representing a reduction in elevation towards the seabed with ' -1 ' and ' -2 ' denotation referring to the position of the OFS in relation to the heat tape; ' -1 ' referring to vertical alignment with the heating tape and ' -2 ' as $100 \mathrm{~mm}$ offset from it. Thus OFS reference 1-1 represents the OFS at the base of the channel directly below the heat tape and ' $3-2$ ' the OFS located above the heat tape offset by $100 \mathrm{~mm}$ separation. The OFS along the heat tape is referenced as ' $2-1$ '. The single length OFS along the top of the sand or the 'seabed' is referenced as ' 4 '.

As a separate and independent point of temperature reference, sheathed, four wire, ceramic platinum resistance thermometers (PT-100) were placed at two locations located at $2.4 \mathrm{~m}$ and $7.0 \mathrm{~m}$ along the channel (see plan view of the channel arrangement in Fig. 1c) and attached to the OFS closest to the heat tape (2-1) using a cable tie. The PT-100 (supplied by Labfacility, UK) were monitored using a Pico Technology PT-104 data logger connected to a computer. Two loggers were used with eight PT-100 sensors.

During activation of the heat tape the surrounding soil temperature would increase and begin to affect the temperature of the water above. It was therefore necessary to recirculate the water using small submersible pumps located along the channel. The water at the surface was also cooled by adding blocks of ice to simulate typical water temperatures around the UK at seabed depth. Figure 2 shows the setup of 
Fig. 2 View from the start of the channel $(0 \mathrm{~m})$ towards the opposite end (at $10 \mathrm{~m}$ ). a During initial setup, b during placement of sand around OFSs, c final setup with retaining partitions where sediment removal later takes place (from Ouyang et al. 2017)
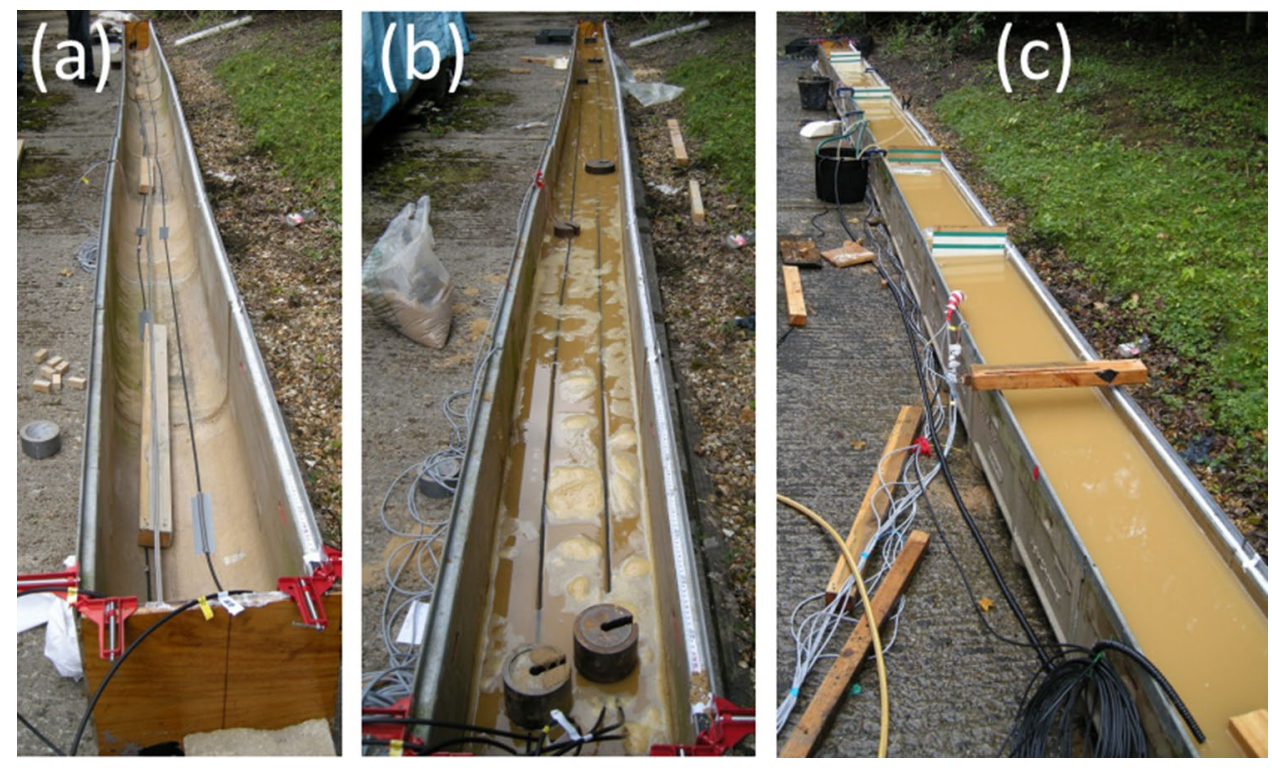

the experiment prior to introduction of sand (a), at a midpoint during laying of the OFS (b), and the final setup with vertical partitions marking intended sediment removal (c).

\section{Fibre optic sensing system}

Following the OFS laying and subsequent burial, the OFS was connected to a Brillouin-based fibre optic distributed temperature and strain analyser known as a DITEST STA-R (manufactured by Omnisens ${ }^{\mathrm{TM}}$ Ltd, Switzerland). The measurements reported by the DITEST STA-R analyser can achieve a minimum spatial resolution of $0.5 \mathrm{~m}$ with temperature accuracy of $0.2{ }^{\circ} \mathrm{C}$, a readout resolution of $5 \mathrm{~cm}$, and the system set-up requires access to both ends of the OFS cable. The analyser sends two counter-propagating waves which can be coupled through a non-parametric non-linear process where the energy transfer from one wave (referred to as 'pump') feeds into the other (called probe). The sensing process identifies the position-dependent frequency information by pulsing one of the optical waves and observing the local coupling on the counter-propagated wave. It allows each measurement to be completed within 7 min with the finest setting mode. The measurements collected by the DITEST STA-R analyser report data are in terms of Brillouin frequency shift which has a linear relationship with temperature, such that $1 \mathrm{MHz}$ equates to a $1^{\circ} \mathrm{C}$ increase.

\section{DTS evaluation during steady conditions}

The initial reference temperature conditions was first established so that later removal of sediment above the OFS at specific locations could be correctly interpreted based on the changes in temperature. To do this the heat tape was activated and the change in temperature $(\Delta \mathrm{T})$ was obtained by taking the difference between two measurements collected by the BOTDA as shown in Fig. 3 .

The temperature development throughout the testing period was based on the initial temperature around $18{ }^{\circ} \mathrm{C}$ reported by the PT-100 sensors, measured within the experimental setup. The temperature changes rapidly when the heating tape is switched on where $50 \%$ of temperature is generated within the first $30 \mathrm{~min}$ and the temperature
Fig. 3 Change in temperature over a full heating cycle as recorded by BOTDA (from Ouyang et al. 2017)

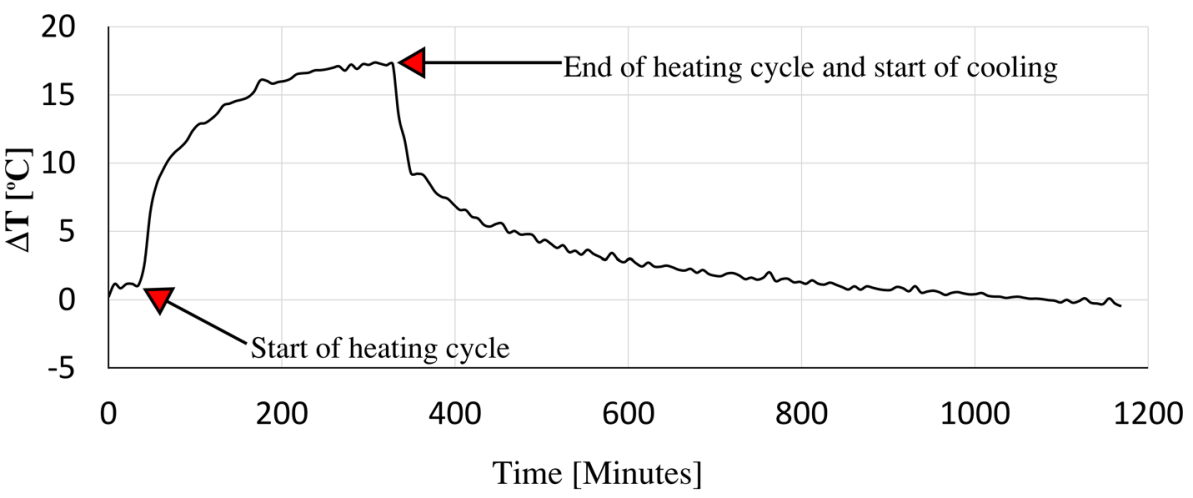


then slowly increases towards eventual stabilisation. After 320 min the heat tape was switched off and rapid initial loss of temperature followed by a gradual temperature reduction led to an eventual ambient temperature condition.

Two heating phases were conducted over the course of two separate days and are shown in Fig. 4 for three arbitrary points along the channel. This comparison serves to demonstrate the reliability of the heating tape system to generate a consistent self-regulating heat source, and potentially highlight any major temperature changes in the experiment between the 2 days. The results in Fig. 4 show that the change in temperature in day 2 was slightly smaller than day 1 which would be consistent with less temperature variability due to an improved soil packing around the OFS (Woodside and Messmer 1961). Some sediment consolidation would be expected over a $24 \mathrm{~h}$ period. Similarly shaped plots indicate that the heat tape generates the same temperature output over the same time step.

The OFS 4 section was laid on the simulated seabed at the interface between the sand and the water to measure water temperature. However water temperature recorded by OFS 4 varied due to partial embedment of the fibre optic cable in some areas which detected conduction heat flux from the sand as well as water temperature (Meininger and Selker 2015). As a result, the readings from OFS 4 were not used and instead point reference readings were monitored using the PT-100 sensors. Variations in temperature between days 1 and day 2 were also compared to understand the correlation in temperature from heat source and adjacent OFS, though changes were found to be insignificant (see Ouyang et al. 2017 for the full appraisal).

\section{Simulation of sediment removal}

The excavation of sediment was undertaken at two zones along the channel once an optimum temperature along the heat tape was established (approximately $24^{\circ} \mathrm{C}$ ). The water temperature was cooled using ice to an average temperature of $12{ }^{\circ} \mathrm{C}$, as recorded by the PT- 100 sensors. One excavation zone was located between $3 \mathrm{~m}$ and $4.5 \mathrm{~m}$ (Zone 1) and the other between $6.5 \mathrm{~m}$ and $8.5 \mathrm{~m}$ (Zone 2). Each zone comprised three stages of reduction in overburden sediment thickness above the OFS. Sediment was retained using vertical partitions and sediment was removed by hand to avoid
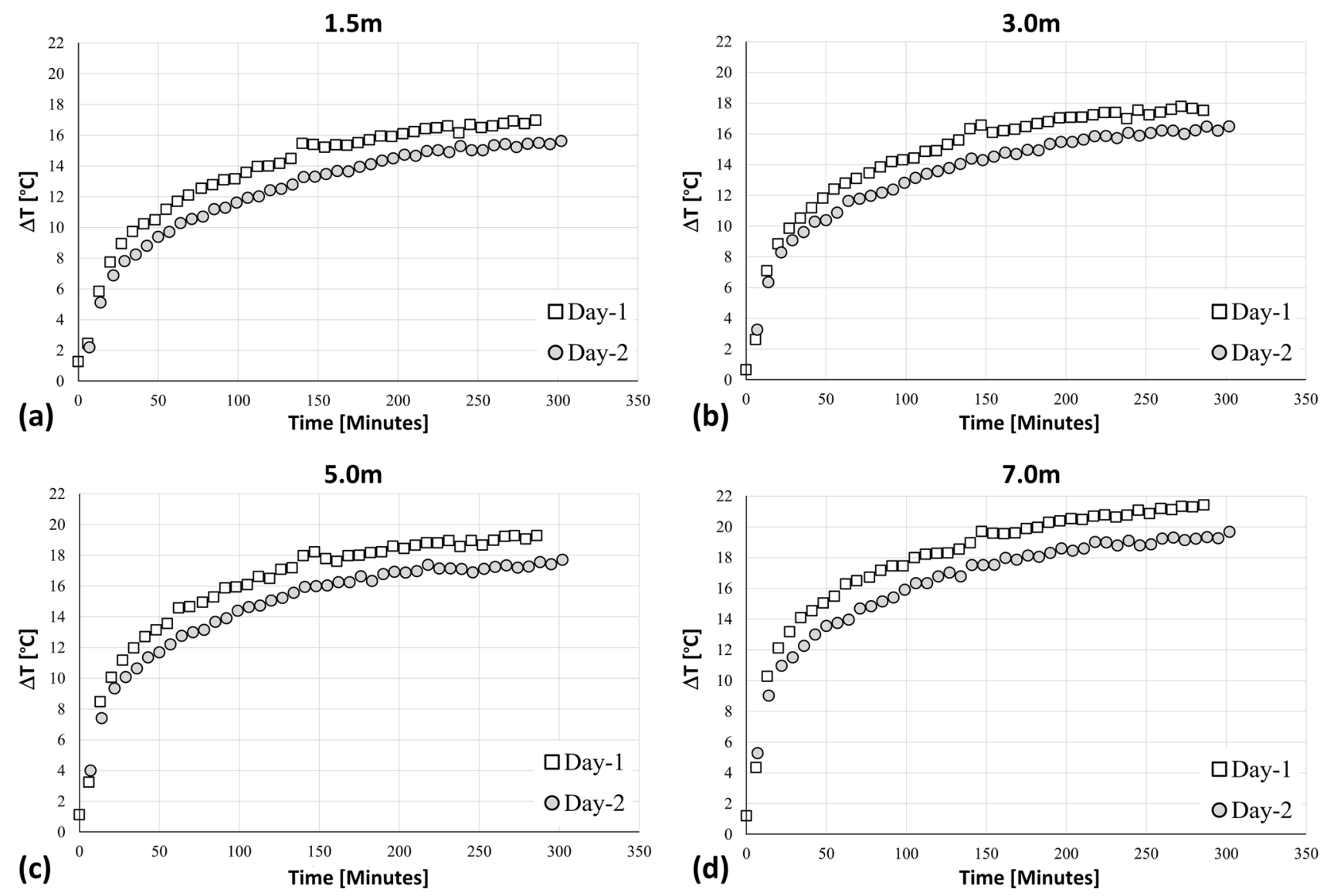

Fig. 4 Temperature comparison between two heating phases measured by OFS $2-1$ on day 1 and day 2 at selected points along the channel adjacent to the heating tape 
damaging the fibre optic cables. A cross-section along the channel in Fig. 5 shows sediment depth at each stage together with the position of OFSs. The excavation at the base was undulating due to slumping of the sand beneath the vertical retaining partitions. No fibre optic cables were exposed in excavation stages 1 and 2 . In the final excavation, stage 3 , fibre optic cables 3-1 and 3-2 were exposed in both zones.

\section{DTS evaluation during simulated scour}

The change in soil temperature at three separate positions on the OFS within the channel is presented in Fig. 6 after the start of the test with three stages of sediment removal. The temperature changes are shown by OFS positions $2-1$, $2-2,3-1$ and $3-2$ but not by OFS positions $1-1$ and $1-2$ which remain covered. Figure $6 a$ and $b$ refer to the positions where sediment removal took place. Figure $6 \mathrm{c}$ shows the temperature change where no sediment was removed though arrows show the time when sediment is removed at the two excavation zones for comparison.

The change in temperature along the fibre optic sensor at and above the heat tape is presented as a heat map in Fig. 7. The contour map generated using MATLAB $®$ represents horizontal slices at four OFS locations along OFSs $2-1,2-2,3-1$ and $3-2$, and shows the temperature development in the channel throughout the entire testing period. The temperature scale has been adjusted between plots because of the magnitude of temperature proximal to the heat tape. The time when each excavation commences is shown on the left side of each map as arrows. There are several elongate hot spots shown in the contour plots, notably in OFS $2-1$ at $6.5 \mathrm{~m}$ and around OFS $3-1$ at $8.7 \mathrm{~m}$. This was considered to be associated with higher density soil around the OFS or the relative installation position of optical fibre sensor to the heating tape. The OFS at position 2-1 was only directly attached to the heating tape at the cable tie positions leading to thermal discrepancies along the channel. The OFS system has detected very subtle changes in temperature variation to the order of $0.3^{\circ} \mathrm{C}$. The positions of sediment removal are clearly shown as reductions in temperature or cold spots.

\section{Part 2. Numerical model and validation}

There are different modelling approaches to interpret DTS data to determine overburden thickness. In general, these strategies rely either on empirical correlations, or on solving the boundary problem. In active DTS, where there is usually only one heat source and its length greater than its diameter, the Line Source Model (Kelvin 1882) can be used. Ingersoll et al. (1954) proposed the use of the line source model for one dimensional analytical simulation of a vertical ground heat exchanger where the heat transfer from a single borehole was treated as a line heat source with constant heat flux in an infinite medium. This was later applied by Mogensen (1983) to estimate ground thermal conductivity. Two or three dimensional numerical models have been developed to analyse spatially distributed subsurface heterogeneities and geothermal gradients (Raymond et al. 2010) and variable boundary conditions (de Lieto Vollaro et al. 2011), the latter being based on the transient heat balance. These techniques can be applied to measure changes in sediment overburden over buried submarine power cables where changes in temperature and ground thermal conductivity are known. The numerical analysis in this paper is based on the line source model and two dimensional finite element method.

\section{Finite element model}

Finite element (FE) modelling is an efficient method in modelling of heat propagation with different kinds of boundary conditions. It simplifies the heat propagation process by allowing a more straightforward interpretation of physical processes. In this experiment, heat transfer happens in the saturated sand based
Fig. 5 Position and excavation stage of sediment along channel

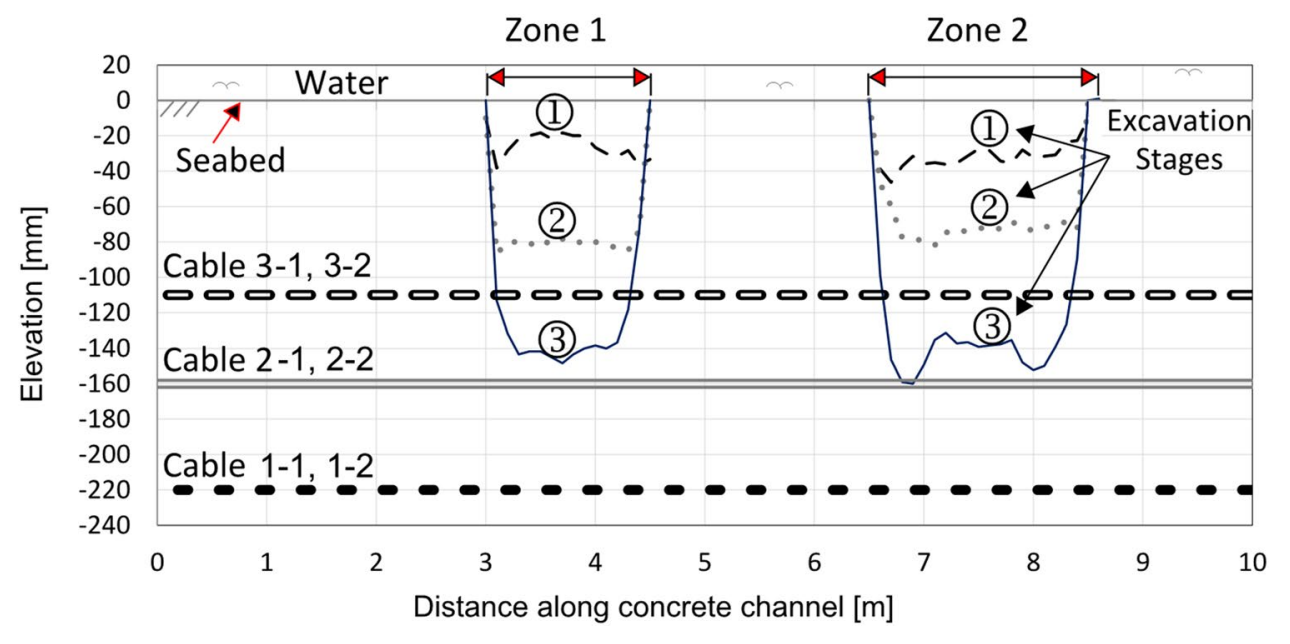



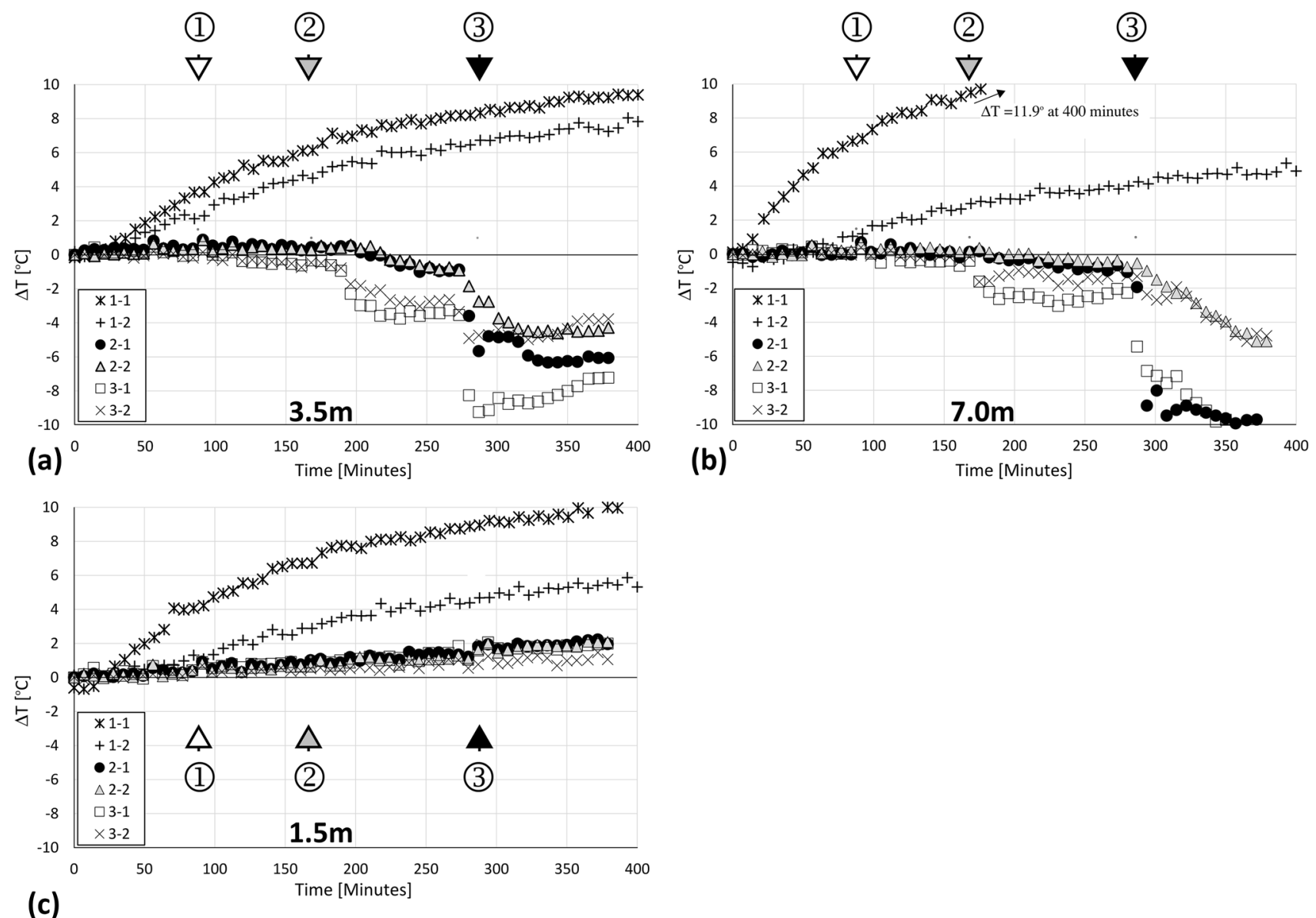

(b)

Time [Minutes]

Fig. 6 Change in temperature at specific points along the channel in response to sediment overburden excavation at $3.5 \mathrm{~m}(\mathbf{a})$ and $7.0 \mathrm{~m}(\mathbf{b})$ with reference to undisturbed sediment at $1.5 \mathrm{~m}(\mathbf{c})$. Arrows and numbers refer to commencement and stage of excavation respectively

on the laws governing the heat conduction. As the groundwater flow is very slow heat convection can be neglected. The thermal properties of the saturated sand are assumed as a saturated porous medium, and calculated as weighted arithmetic values of single components, including water and sand grains. The weights are the volume fractions. Under this assumption, the homogeneous material mass density $\rho$, heat capacity $c$ and thermal conductivity $k$ can be calculated by:

$\rho=(1-\mathrm{n}) \rho_{s}+\mathrm{n} \rho_{w}$

$\mathrm{c}=(1-\mathrm{n}) \mathrm{c}_{s}+\mathrm{nc}_{w}$

$k=(1-\mathrm{n}) \mathrm{k}_{\mathrm{s}}+\mathrm{nk}_{\mathrm{w}}$

where subscripts $s$ and $w$ donate the solid and water phases and $\mathrm{n}$ is the porosity.

The governing equation of the heat transport process in porous medium can be written as,

$-\sum_{\mathrm{i}=1}^{3} k \frac{\partial^{2} \mathrm{~T}}{\partial \mathrm{x}_{\mathrm{i}}^{2}}+\mathrm{c} \frac{\mathrm{dT}}{\mathrm{dt}}=\mathrm{Q}$ where $\mathrm{T}$ is the temperature and $\mathrm{Q}$ is the heat source.

The finite element method is then introduced to solve the partial differential equations above. The first step is discretising these equations in their space dimensions. The discretisation is carried out locally over small regions of simple but arbitrary shapes (the finite elements). This results in matrix equations relating the input at specified points in the elements to the output at these same points. In order to solve equations over large regions, matrix equations for the smaller sub-regions can be added together node by node, resulting in global matrix equations.

In the finite element technique, the continuous variable $\mathrm{T}$ is approximated by $\tilde{T}$ in terms of its nodal values $\mathrm{T}_{1}, \mathrm{~T}_{2}$ and $\mathrm{T}_{3}$ through simple functions of the space variable called shape functions. That is:

$\tilde{T}=\mathrm{N}_{\mathrm{i}} \mathrm{T}_{\mathrm{i}}$

where $\mathrm{N}_{\mathrm{i}}=\left[\mathrm{N}_{1} \mathrm{~N}_{2} \mathrm{~N}_{3}\right]$ is the shape function of each nodes, $\mathrm{T}_{\mathrm{i}}=\left[\begin{array}{ll}\mathrm{T}_{1} \mathrm{~T}_{2} \mathrm{~T}_{3}\end{array}\right]^{\mathrm{T}}$. When (5) is substituted into (4), we have:

$-\nabla^{\mathrm{T}} \mathrm{k} \nabla\left(\mathrm{N}_{\mathrm{i}} \mathrm{T}_{\mathrm{i}}\right)+\mathrm{c}_{\mathrm{sw}} \frac{\mathrm{d}}{\mathrm{dt}}\left(\mathrm{N}_{\mathrm{i}} \mathrm{T}_{\mathrm{i}}\right)=\mathrm{N}_{\mathrm{i}} \mathrm{q}_{\mathrm{i}}$ 


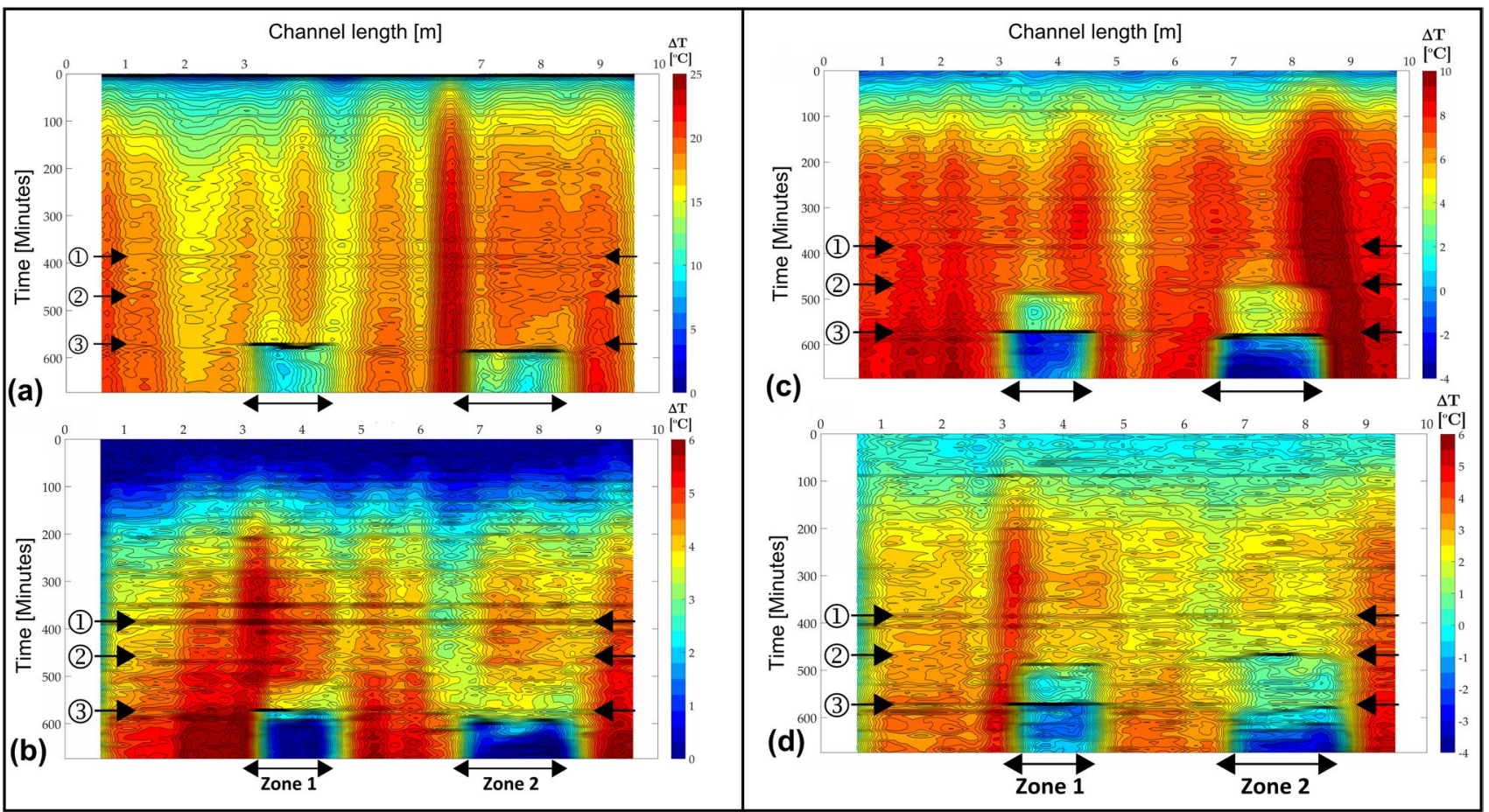

Fig. 7 Temperature contour map showing horizontal slices at fibre optic cable positions. a OFS $2-1$, b OFS $2-2$, c OFS $3-1$ and d OFS $3-2$

According to the Galerkin method, we could get a matrix equation as:

$\left[\mathrm{M}_{\mathrm{TT}}\right] \frac{\mathrm{dT}_{\mathrm{i}}}{\mathrm{dt}}+\left[\mathrm{K}_{\mathrm{TT}}\right] \mathrm{T}_{\mathrm{i}}=\mathrm{Q}_{\mathrm{i}}$

$\left[\mathrm{K}_{\mathrm{TT}}\right]=\mathrm{k} \iint\left[\frac{\partial \mathrm{N}_{\mathrm{i}}}{\partial \mathrm{x}} \frac{\partial \mathrm{N}_{\mathrm{j}}}{\partial \mathrm{x}}+\frac{\partial \mathrm{N}_{\mathrm{i}}}{\partial \mathrm{y}} \frac{\partial \mathrm{N}_{\mathrm{j}}}{\partial \mathrm{y}}+\frac{\partial \mathrm{N}_{\mathrm{i}}}{\partial \mathrm{z}} \frac{\partial \mathrm{N}_{\mathrm{j}}}{\partial \mathrm{z}}\right] \mathrm{dxdy}$

$\left[\mathrm{M}_{\mathrm{TT}}\right]=\mathrm{c}_{\mathrm{sw}} \iint\left[\mathrm{N}_{\mathrm{i}} \mathrm{N}_{\mathrm{j}}\right] \mathrm{dxdy}$

In this equation, $\left[\mathrm{K}_{\mathrm{TT}}\right]$ is the element stiffness matrix, and $\left[\mathrm{M}_{\mathrm{TT}}\right]$ is the element mass matrix.

In order to solve this time dependent problem, the linear interpolations method is used with a time step $\Delta$ t. So $T_{i}$ can be written as $\theta \mathrm{T}_{\mathrm{i}}^{1}+(1-\theta) T_{\mathrm{i}}^{0}$, where $\theta$ is a constant between 0 and $1, T_{i}^{1}$ is the temperature tensor at time step 1 and $T_{i}^{0}$ is the temperature tensor at time step $0 . \frac{\mathrm{dT}_{\mathrm{i}}}{\mathrm{dt}}$ can be written as $\frac{T_{i}^{1}-T_{i}^{0}}{\Delta t}$. Hence, Eq. (7) can be written as:

$\left[\mathrm{M}_{\mathrm{TT}}\right] \frac{\mathrm{T}_{\mathrm{i}}^{1}-\mathrm{T}_{\mathrm{i}}^{0}}{\Delta \mathrm{t}}+\theta\left[\mathrm{K}_{\mathrm{TT}}\right] \mathrm{T}_{\mathrm{i}}^{1}+(1-\theta)\left[\mathrm{K}_{\mathrm{TT}}\right] \mathrm{T}_{\mathrm{i}}^{0}=\theta \mathrm{Q}_{\mathrm{i}}^{1}+(1-\theta) \mathrm{Q}_{\mathrm{i}}^{0}$

In this study, $\theta=1$. An implicit solution is written as:

$\frac{1}{\Delta \mathrm{t}}\left[\mathrm{M}_{\mathrm{TT}}\right] \mathrm{T}_{\mathrm{i}}^{1}+\left[\mathrm{K}_{\mathrm{TT}}\right] \mathrm{T}_{\mathrm{i}}^{1}=\mathrm{Q}_{\mathrm{i}}^{1}+\frac{1}{\Delta \mathrm{t}}\left[\mathrm{M}_{\mathrm{TT}}\right] \mathrm{T}_{\mathrm{i}}^{0}$
A finite element model was built to simulate the physical experiment. The channel was assumed to be long enough so that the test could be simplified as a problem of transient heat conduction within a plane. A two dimensional FE mesh was first generated to represent the cross section of the channel as shown in Fig. 8. The model comprised four components: sand, water, concrete channel and ground. To ensure that the heat distribution within the channel was not affected by the boundary conditions, the ground was modelled as $6 \mathrm{~m}$ wide and $3 \mathrm{~m}$ high. The temperature at the side and base of the ground were fixed as initial temperature. Heat insulation conditions were then satisfied for the upper boundary and sides of channel. In the FE model, the heat source refers to a set of nodes where a total heat production rate $(75 \mathrm{~W})$ was applied. The porosity of sand was chosen as 0.3 with other parameters chosen for the model obtained from DECC (2011), as shown in Table 1.

Because a small error in the installation of fibre optic cables can cause a large variation in the temperature detected by OFS, the model calibration was performed by varying the distance of optical fibre sensor to heating tape so that the simulated results were similar to the experiment data. Figure 9 shows the curve matching between the experimental data and the modelling results for the heating and cooling of the OFS along the heat tape. During the heating process, both numerical and experimental data increased steadily to a peak value about $17{ }^{\circ} \mathrm{C}$, followed by a sharp decrease toward the initial temperature. The distance between the heat 
Fig. 8 Construction of an FE model showing the main elements and nodes within the channel and the boundary conditions

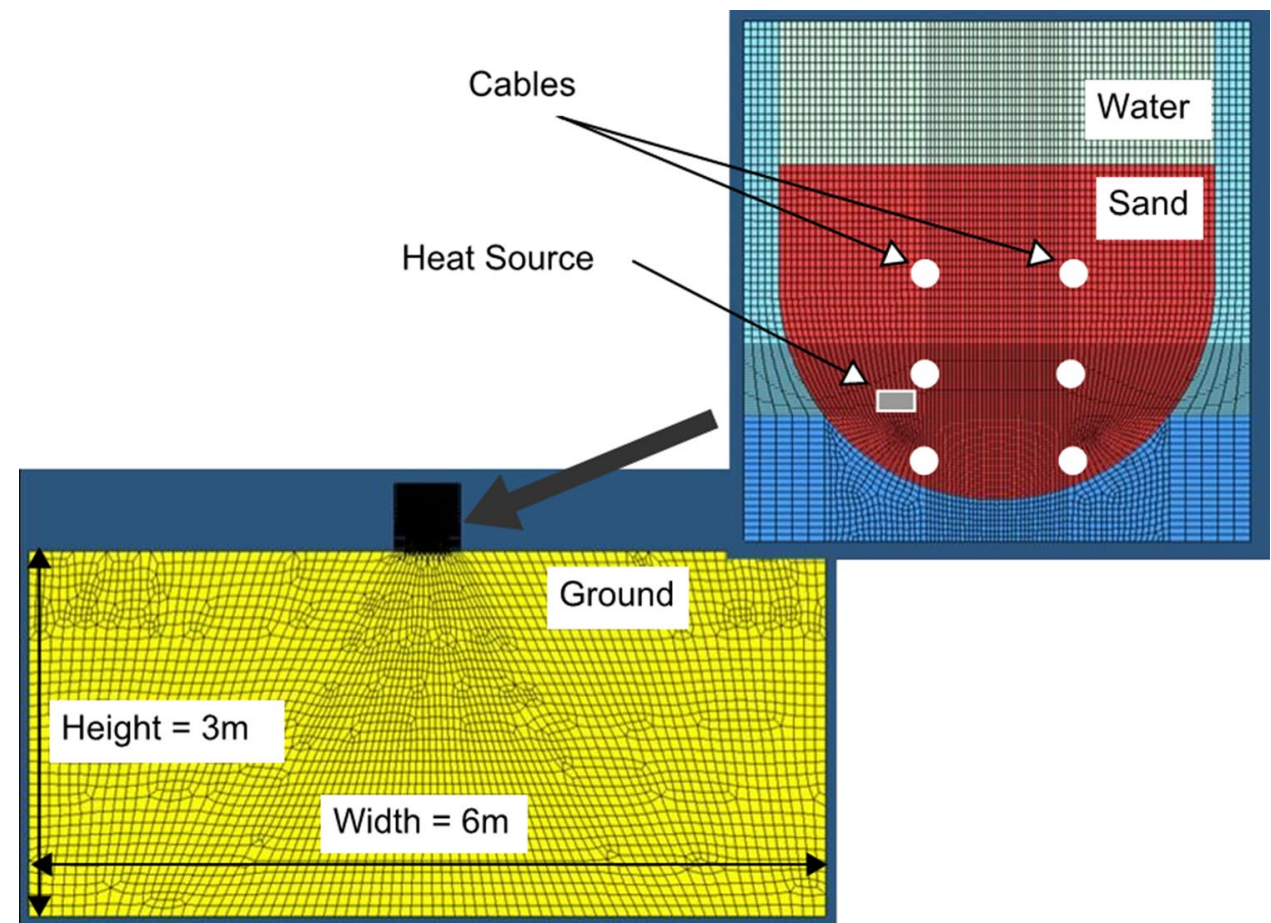

Table 1 Parameters used in the numerical model of the channel (DECC 2011; Rui and Soga 2018)

\begin{tabular}{lllll}
\hline Parameter & Sand & $\begin{array}{l}\text { Channel } \\
\text { (con- } \\
\text { crete })\end{array}$ & Water & Ground \\
\hline Thermal conductivity $[\mathrm{W} /(\mathrm{m} . \mathrm{K})]$ & 2.0 & 1.5 & 0.6 & 1.6 \\
Thermal capacity $\left(\mathrm{kJ} / \mathrm{m}^{3} \mathrm{~K}\right)$ & 3200 & 2400 & 4200 & 2800 \\
\hline
\end{tabular}

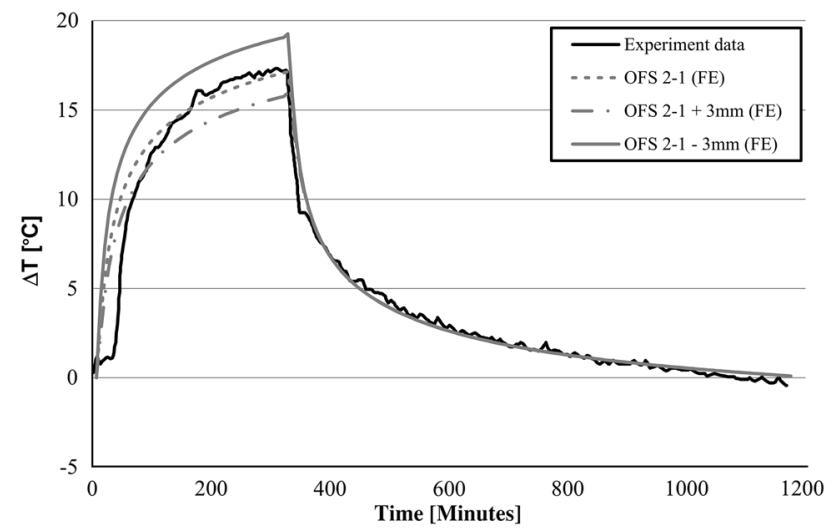

Fig. 9 Experimental data and numerical result of OFS 2-1 for complete heating and cooling cycle of the heat tape

source and OFS cable played an important role due to the sharp change in the temperature distribution with distance around the heat source. Assuming the cable 2-1 moved
$3 \mathrm{~mm}$, an obvious change in temperature propagation has been observed. When the cable is $3 \mathrm{~mm}$ closer, the peak temperature increased about $2{ }^{\circ} \mathrm{C}$.

To simulate the experimental procedure of sediment removal described in "DTS evaluation during steady conditions" Section, the finite element analysis involved the following calculation steps:

(1) Initial condition The temperature of all components, including sand, water, channel and ground, were set as initial temperature.

(2) Activation of the heat tape A heat production rate (75W) applied to the six nodes representing the OFS, as shown in Fig. 8.

(3) Cooling of water The temperature of water relative to the initial temperature, was set as $\Delta \mathrm{T}=-4{ }^{\circ} \mathrm{C}$ during the cooling stage, which assumes the sea water temperature is $4{ }^{\circ} \mathrm{C}$ lower than initial soil temperature.

(4) Excavation Following the excavation procedure in the experiment, as shown in Fig. 5, the excavated part of sand where the OFS cable was exposed was changed to that of the water component, set as fixed temperature $\Delta \mathrm{T}=-4{ }^{\circ} \mathrm{C}$.

\section{FE validation and discussion}

The data shown in Fig. 9 is the average temperature profile along the channel length, but the elongate hot spots in Fig. 7 indicate that the temperature is not uniform along the 

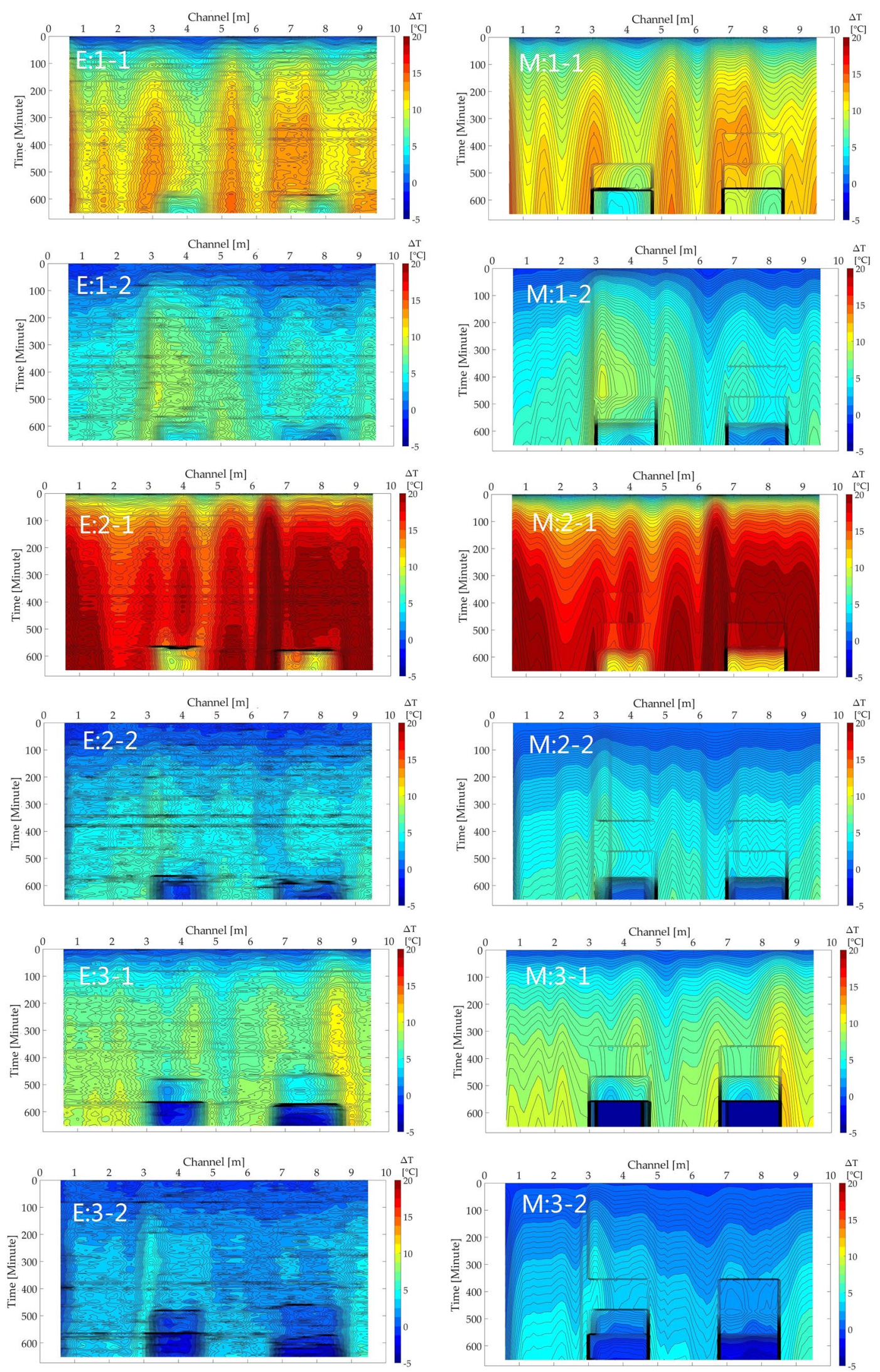

Fig. 10 Heat map along the channel during removal of the overburden at each OFS cable elevation for the experimental data (E) and simulated using the numerical model (M) 
channel length, due to variations in the installation positions of the optical fibre cable and the heating tape. Hence, the positions of each measuring point on OFS was adjusted in the range of $\pm 2 \mathrm{~cm}$ in the FE model for each cross section to match the experimental data. Figure 10 shows the heat map simulated by the numerical model (M) alongside that obtained by experimental measurement (E) for each OFS location. Although less fluctuation can be observed in the FE results, the overall trend in temperature changes are quite similar between experiment data and FE results. For OFS 1-1 and OFS 1-2, which are beneath the heat tape and distant from the cooled surface water, the influence of excavation on temperature change is limited to about $\Delta \mathrm{T}=5{ }^{\circ} \mathrm{C}$ maximum. As OFS $2-1$ is closest to the heat tape, the temperature increases sharply to about $\Delta \mathrm{T}=20^{\circ} \mathrm{C}$ during the heating stage, and then decreases to about $\Delta \mathrm{T}=10^{\circ} \mathrm{C}$ during excavation. Some parts of OFS 3-1 and 3-2 were exposed to the cooled water in the final excavation, and therefore a sharp decrease to $\Delta \mathrm{T}=-2 \sim-4{ }^{\circ} \mathrm{C}$ is shown in the heat map contour.

Similarly, the change in temperature caused by the excavation at specific locations can also be modelled by FE analysis as shown in Fig. 11 where the peak temperature is set as the baseline so the effects of excavation can be highlighted. Very small changes in temperature of OFS 1-1 and 1-2 were observed, because the large distance between fibre optical cables and seabed reduce the effect of changes in sediment overburden. OFS cables $2-1$ and 2-2 were installed at the same elevation, but the excavation induced temperature decreases were different. The temperature of OFS 2-1 decreases to about $\Delta \mathrm{T}=-6{ }^{\circ} \mathrm{C}$ at $3.5 \mathrm{~m}$ and $\Delta \mathrm{T}=-9{ }^{\circ} \mathrm{C}$ at $7.0 \mathrm{~m}$. For OFS $2-2$, the temperature at $360 \mathrm{~min}$ is about $\Delta \mathrm{T}=-4.5{ }^{\circ} \mathrm{C}$ at $3.5 \mathrm{~m}$ and $\Delta \mathrm{T}=-4{ }^{\circ} \mathrm{C}$ at $7.0 \mathrm{~m}$. This difference is caused by the large difference of peak temperature between these two OFS cable locations, shown in Fig. 11. Similar results can be found in OFS cables 3-1 and 3-2. For OFS 3-1, the FE results show that the temperature does not change much in the first and second excavation, but decreases sharply to $\Delta \mathrm{T}=-9.5^{\circ} \mathrm{C}$ in the last excavation. For OFS 3-2, the decrease in OFS temperature is gentle, and the final change in temperature is about $\Delta \mathrm{T}=-4.5^{\circ} \mathrm{C}$. However, once exposed to water, the OFS cables (3-1 and 3-2) could not detect the change in overburden anymore. Hence, it can be concluded that the fiber optic cable installed close to the heat tape is not sensitive to the small change in sediment overburden (first and second excavation), but has a large measurement range compared to the OFS cables close to seabed.

The aim of this study is to estimate the thickness of the sediment layer on top of the OFS without any sediment removal. The steady state value of cable temperature by adjusting the sediment thickness in the FE analysis can be used to solve this problem. Figure 12 shows the relationship between thickness of sediment overburden and OFS temperature. It is shown that the temperature of Cable 2-1 changes sharply when the thickness decreases, which indicates that Cable 2-1 is most sensitive to detect the initial thickness of sediment overburden among all cables. In addition, when the thickness of sediment overburden reduces from $200 \mathrm{~mm}$ to $0 \mathrm{~mm}$, the temperature of Cable 3-1 and Cable 2-2 reduces about $15^{\circ} \mathrm{C}$ and $10{ }^{\circ} \mathrm{C}$ respectively. This indicates that two factors determine the sensitivity of OFS on initial thickness of sediment overburden. The first is the distance between heat source and OFS. The second is the distance between water level and the OFS.

\section{Part 3: Parametric study}

The finite element analysis in this paper involves a parametric study to understand the thermal changes that may take place during overburden reduction in different soil types. The thermal conductivity coefficient is the most important thermal property of the soil as it controls the main heat transfer mechanism for transient state analysis, although the heat flow at the interface between sediments and water should be the same in steady state for different $\mathrm{k}$ values. The effect of changing the soil type, and the response to changes in overburden depth, can be demonstrated by conducting simulations with different thermal conductivity values. The parameters used for the model are shown in Table 2.

\section{Parametric study results and discussion}

Figure 13 shows the change in temperature of OFS 2-1 with different thermal conductivities for the heating and cooling cycle by the heat tape. When the thermal conductivity is 0.5 times the original value, the largest change in temperature is about $\Delta \mathrm{T}=23{ }^{\circ} \mathrm{C}$, and with 2.0 times thermal conductivity, the largest change in temperature is only about $\Delta \mathrm{T}=13^{\circ} \mathrm{C}$. With lower thermal conductivity, the temperature of OFS $2-1$ change is higher due to less heat transferred to the cold water. The results show that the temperature change is greatly affected by the thermal conductivity of soil.

Figures 14 and 15 show the change in temperature at selected OFS locations caused by the excavation at location $3.5 \mathrm{~m}$ and $7.0 \mathrm{~m}$ along the channel. As expected from the effect of the thermal conductivities, the temperature with 0.5 times thermal conductivity proceeds at a slightly higher 

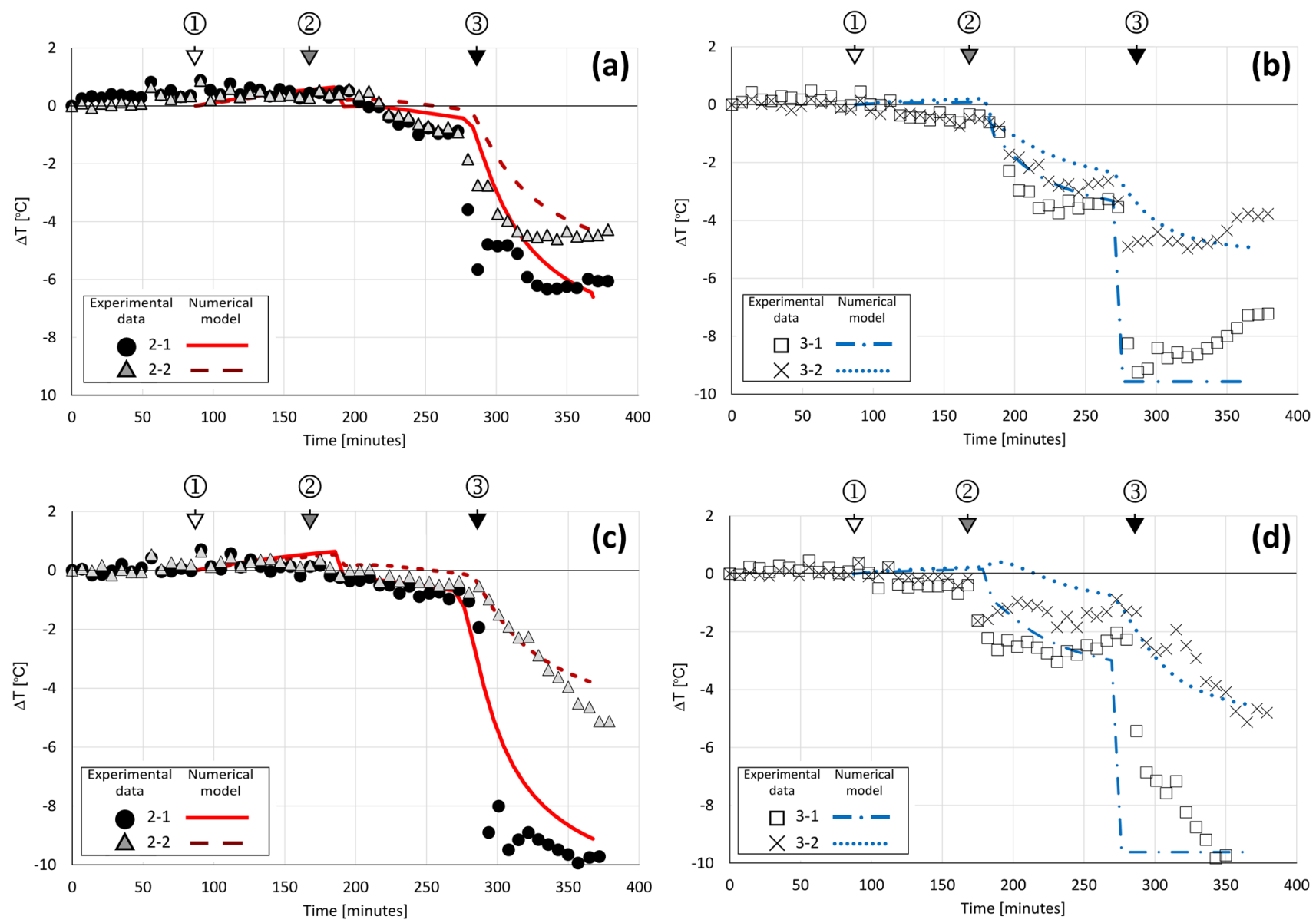

Fig. 11 Change in temperature at specific points along the channel in response to sediment overburden excavation: At $3.5 \mathrm{~m}(\mathbf{a}$ and $\mathbf{b})$; at $7.0 \mathrm{~m}$ (c and d)

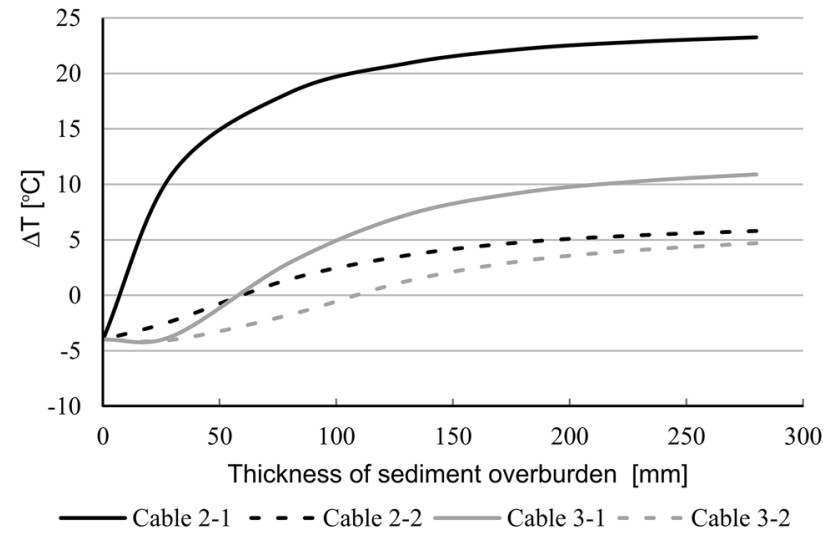

Fig. 12 Detection of thickness of sediment overburden
Table 2 Parameters used for parametric study

\begin{tabular}{lllll}
\hline $\begin{array}{l}\text { Thermal conductivity } \\
\mathrm{k}[\mathrm{W} /(\mathrm{m} \mathrm{K})]\end{array}$ & Sand & $\begin{array}{l}\text { Channel } \\
\text { (concrete) }\end{array}$ & Water & Ground \\
\hline Case $1(\mathrm{k} \times 0.5)$ & 1.0 & 1.5 & 0.6 & 1.6 \\
Case $2(\mathrm{k} \times 1.0)$ & 2.0 & 1.5 & 0.6 & 1.6 \\
Case $3(\mathrm{k} \times 2.0)$ & 4.0 & 1.5 & 0.6 & 1.6 \\
\hline
\end{tabular}

value (by about $1-2{ }^{\circ} \mathrm{C}$ ) than other two cases at the first and second excavation step. With twice the thermal conductivity, the increase in temperature during the first excavation is very limited, at about $0-0.5{ }^{\circ} \mathrm{C}$. During the second excavation, all the OFS cable temperature curves show more obvious 


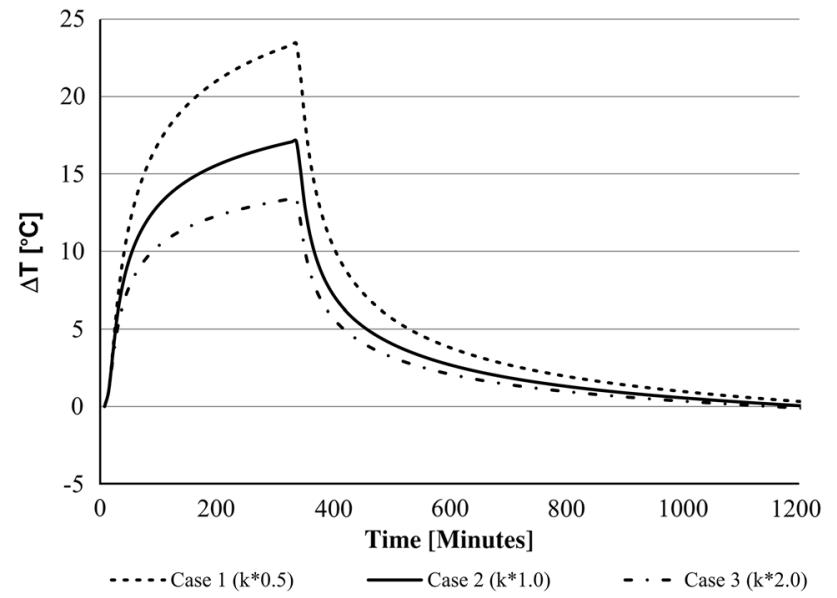

Fig. 13 Effects of changing thermal conductivity of sand on the temperature of OFS 2-1 for complete heating and cooling cycle of the heat tape

decrease than other two cases with lower thermal conductivity. This seems reasonable, because lower thermal conductivity would slow down the heat transfer in the soil and hence make the OFS less sensitive to the sediment removal. At the final excavation, a sharper decrease in temperature is observed for the 0.5 times thermal conductivity case. This is because lower thermal conductivity would lead to a higher peak temperature before excavation as discussed above, hence the OFS measured temperature can decrease more when the excavation level is close to the OFS. Therefore, soil with higher thermal conductivity can enhance the ability of OFS cable to detect the small changes in sediment overburden, but poor thermal conductivity can make the variation in temperature readings of OFS more significant due to the large changes in sediment overburden. Hence, thermal conductivity of soil is an important factor to consider in the design of an OFS monitoring system.

On the other hand, changing the thermal conductivity of soil has a large effect on the sensitivity of OFS on detecting the sediment overburden thickness, as shown in Fig. 16. It is shown that when the thermal conductivity decreased to 0.5 times the original value, the OFS temperature increased sharply when the sediment overburden thickness increases. When sediment overburden thickness is $270 \mathrm{~mm}$, this value is about $41.9^{\circ} \mathrm{C}, 8.7^{\circ} \mathrm{C}, 18.9^{\circ} \mathrm{C}$ and $7.5^{\circ} \mathrm{C}$ for cable $2-1$, $2-2,3-1$ and 3-2 respectively. But when using 2 times the original value, the OFS temperature decreased to about
$13{ }^{\circ} \mathrm{C}, 3.6{ }^{\circ} \mathrm{C}, 6.2{ }^{\circ} \mathrm{C}$ and $2.8{ }^{\circ} \mathrm{C}$ respectively. Therefore, with lower thermal conducty of soil, the OFS is more sensitive to the change in sediment overburden thickness.

\section{Conclusions}

With the heat generated from the heat tape increasing linearly during the experiment, the change in sediment thickness can be observed as both a stabilisation and/or reduction in temperature detected by OFS cables. Despite a difference in temperature between heat tape and surface water a minimum of $10 \mathrm{~mm}$ sediment removal could be detected from the temperature in the soil medium. The effective detection of sediment disturbance between excavation zones also demonstrates the sensitivity of the DTS system to capture temperature change throughout the test.

The numerical code using the line source model, incorporating a transient heat balance, showed that the experimental data could match both the thermal dissipation of the heat source and the change in boundary conditions.

The thermal conductivity of the soil depends on the grain size and density as well as grain type of the material. Sand was used in this experiment for ease of setup and elimination of air during placement above the optical fibre and the heat tape. By altering the thermal conductivity of the material changes in sediment overburden could be simulated. In a field scenario changes in sediment overburden could be easily measured using bathymetry and compared to fluctuation in the thermal response recorded by the OFS. The thermal conductivity of the sediment covering the OFS cables could be measured in situ using a probe and thus measurement of differential sediment thickness caused by scour could be monitored. The numerical code demonstrated in this experiment using DTS could potentially be a powerful tool for assessing seabed erosion along heat generating assets such as power cables. However the geometry of the experiment is much smaller than in the real field situation and the results may be influenced by boundary effects created by other variability. A large-scale field test using the principles described in this paper to investigate the thermal effect of changes in changing sediment overburden is currently the subject of a future study.

Should a field test be successful, Brillouin back-scattered distributed sensing has the potential to monitor sediment 
Cable 2-1
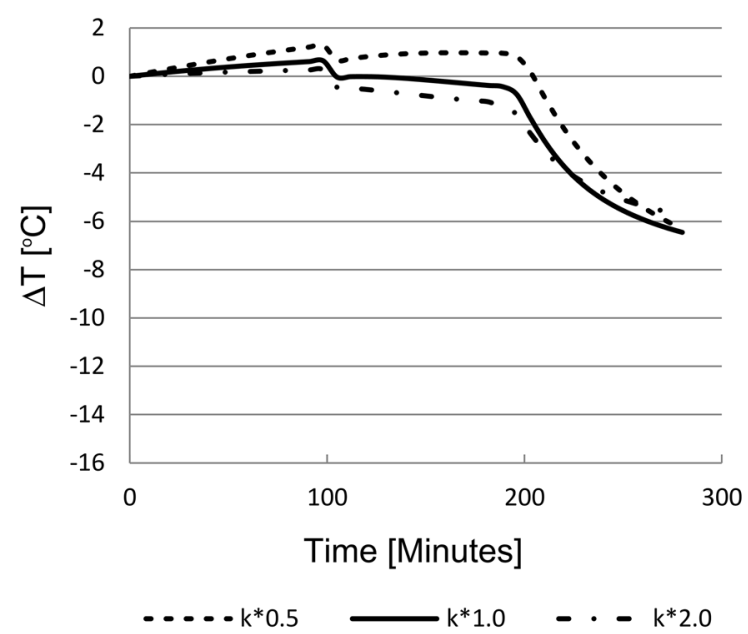

Cable 3-1

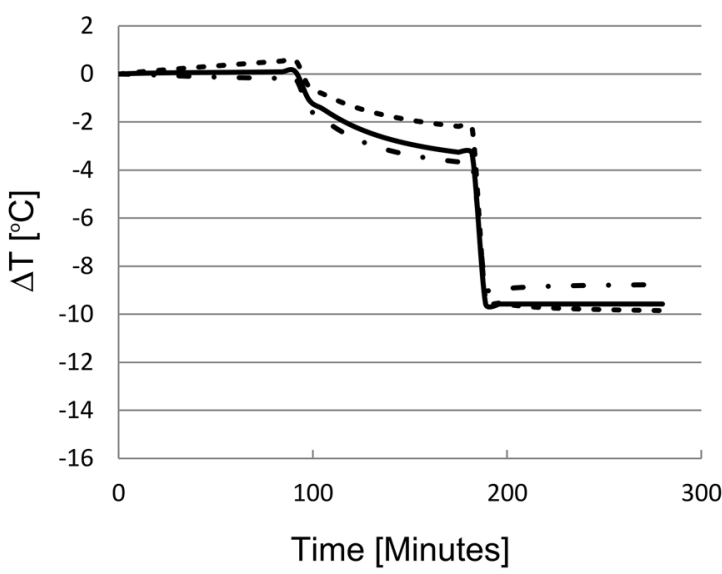

- . - - $\mathrm{k}^{*} 0.5 \longrightarrow \mathrm{k}^{*} 1.0 \quad-\cdots \mathrm{k}^{*} 2.0$

Fig. 14 Change of temperature at $3.5 \mathrm{~m}$ due to removal of overburden

overburden above power cables up to at least $60 \mathrm{~km}$ from one commercially available analyser channel, which is more than sufficient for most wind farm inter-arrays. Such techniques could reduce the reliance on, or enhance the interpretation of data from, routine seabed surveys to locate scour pits. This would be especially beneficial during months
Cable 2-2
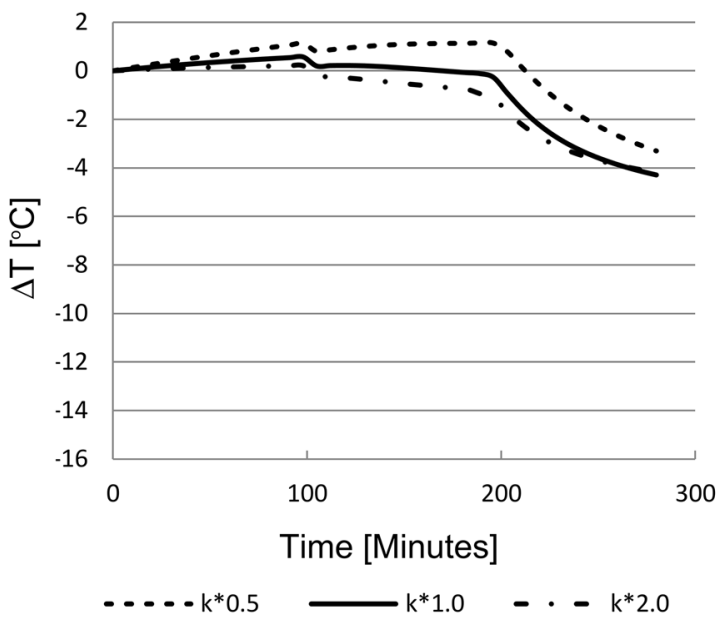

Cable 3-2

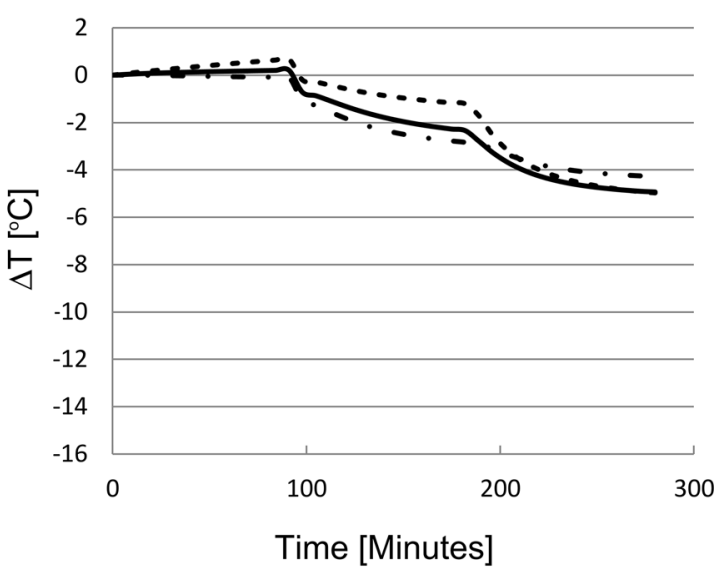

- - - $\mathrm{k}^{*} 0.5 \longrightarrow \mathrm{k}^{*} 1.0 \quad-\cdots \mathrm{k}^{*} 2.0$

when treacherous sea-state conditions limit the deployment of geophysical arrays and when storm surges may amplify seabed erosion due to strong currents or even bed liquefaction. Active fibre optic monitoring could also aid in monitoring scour mitigation during rock dumping activities to ensure successful remediation. 
Cable 2-1
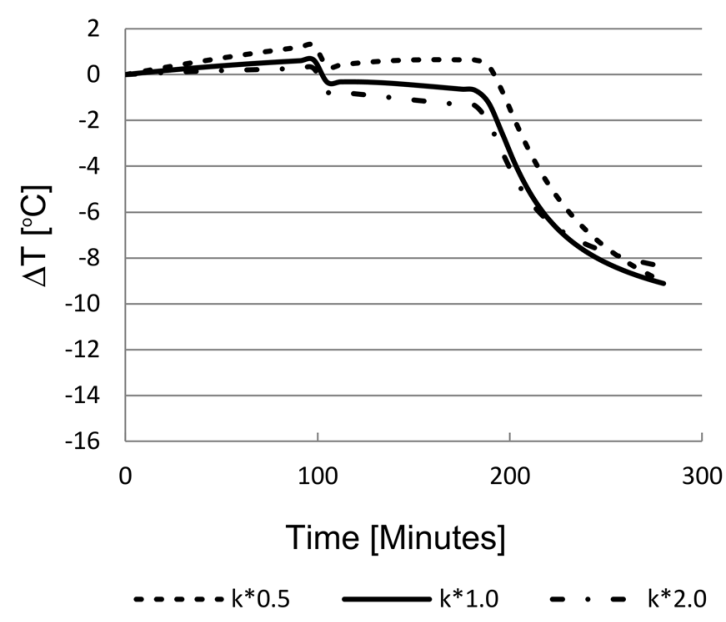

Cable 3-1

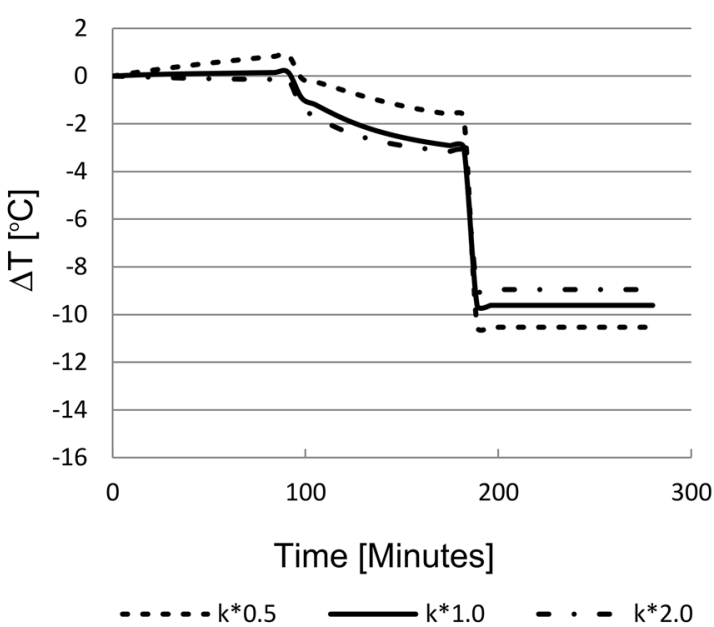

Fig. 15 Change of temperature at $7.0 \mathrm{~m}$ due to removal of overburden

Open Access This article is distributed under the terms of the Creative Commons Attribution 4.0 International License (http://creativeco
Cable 2-2

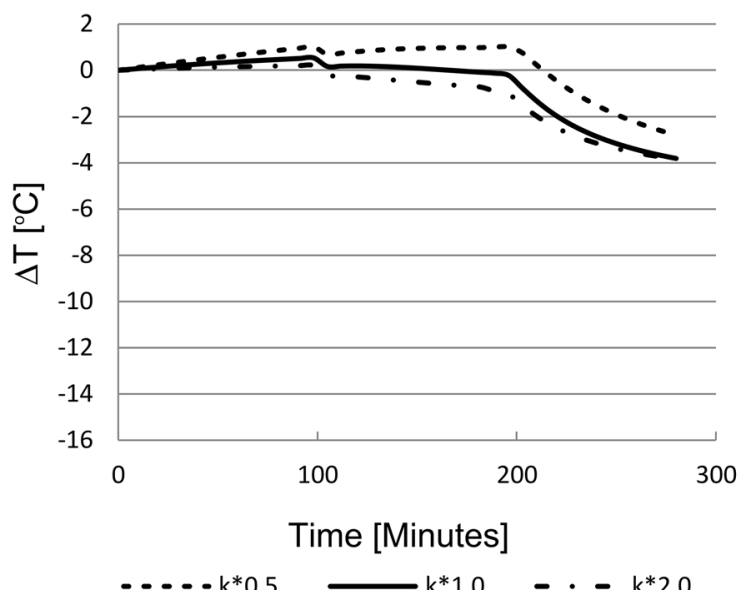

Cable 3-2

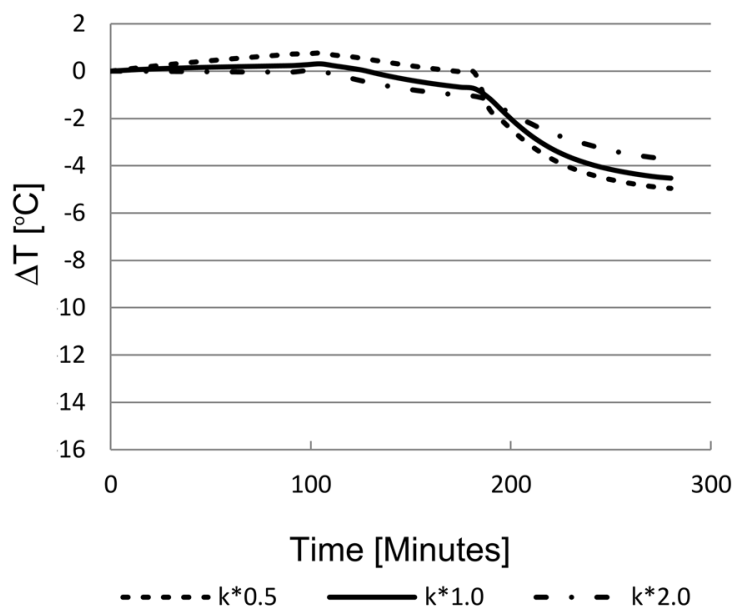

mmons.org/licenses/by/4.0/), which permits unrestricted use, distribution, and reproduction in any medium, provided you give appropriate credit to the original author(s) and the source, provide a link to the Creative Commons license, and indicate if changes were made. 
Cable 2-1

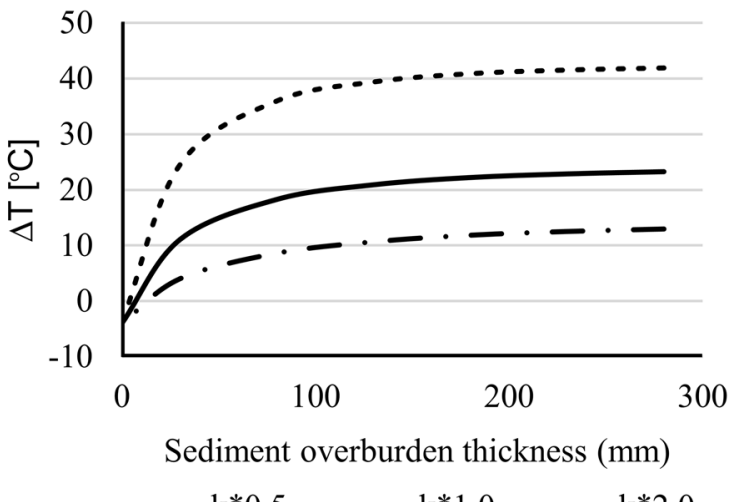

- - $\mathrm{k}^{*} 1.0-0.5-\mathrm{k}^{*} 2.0$

Cable 3-1

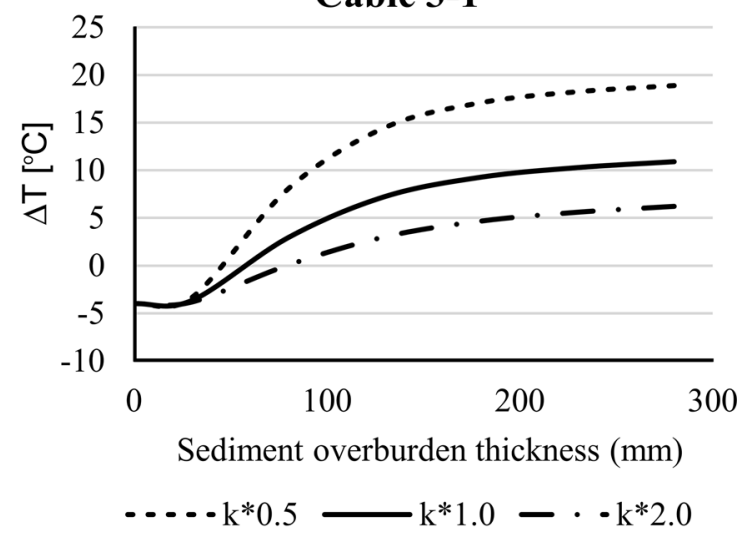

Cable 2-2

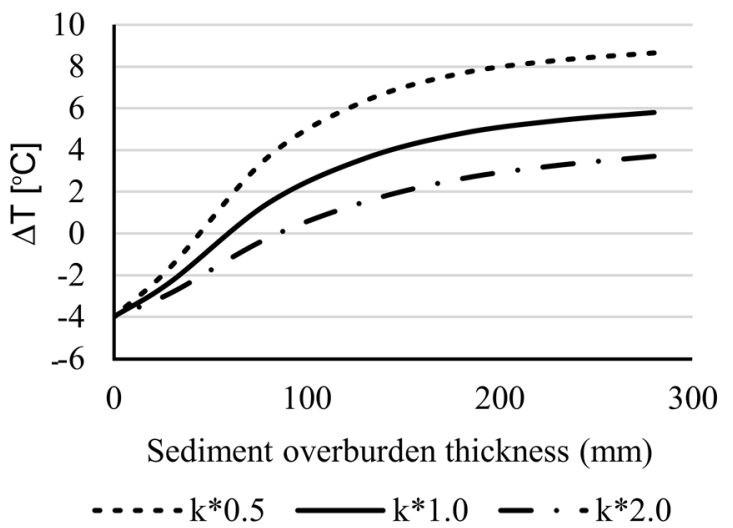

Cable 3-2

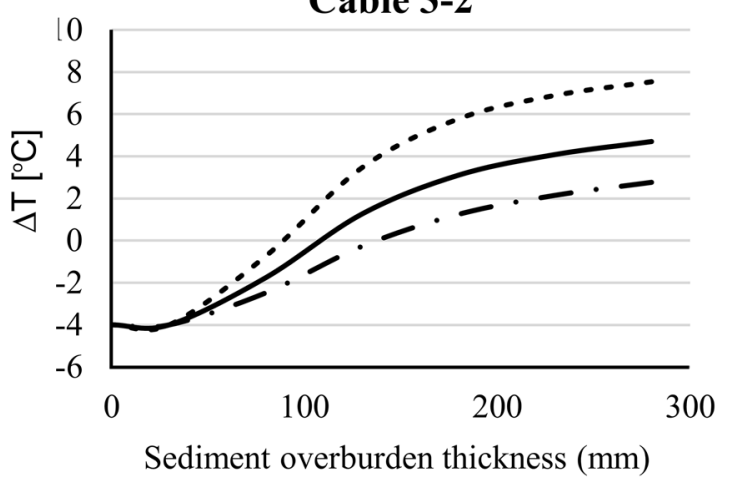

- $-\mathrm{k}^{*} 0.5 \longrightarrow \mathrm{k}^{*} 1.0-\cdots \mathrm{k}^{*} 2.0$

Fig. 16 Effects of soil thermal conductivity on detection of thickness of sediment overburden

\section{References}

Arnon A, Lensky NG, Selker JS (2014) High-resolution temperature sensing in the Dead Sea using fiber optics. Water Resour Res 50:1756-1772. https://doi.org/10.1002/2013WR014935

Artieres O, Beck Y-L, Guidoux C (2012) Scour erosion detection with a fiber optic sensor-enabled geotextile. In: Proceedings of the 6th International Conference on Erosion, Paris, 27-31 August, pp 1353-1359

Bourne-Webb PJ, Amatya B, Soga K, Amis T, Davidson C, Payne P (2009) Energy pile test at Lambeth College, London: geotechnical and thermodynamic aspects of pile response to heat cycles. Géotechnique 59(3):237. https://doi.org/10.1680/geot.2009.59.3.237

Bray EN, Dunne T (2017) Observations of bedload transport in a gravel bed river during high flow fibre-optic DTS methods. Earth Surf Proc Land 42:2184-2198. https://doi.org/10.1002/esp.4164

de Lieto Vollaro R, Fontana L, Vallati A (2011) Thermal analysis of underground electrical power cables buried in non-homogeneous soils. Appl Therm Eng 31(5):772-778. https://doi.org/10.1016/j. applthermaleng.2010.10.024

DECC (2011) Msc 022: Ground heat exchanger look-up tables. Issue 1.0. Technical report, Department of Energy and Climate Change, London, UK

Grayson S, Gonzalez Y, England K, Bidyk R, Pitts SF (2015) Monitoring acid stimulation treatments in naturally fractured reservoirs with slickline distributed temperature sensing. Soc Petroleum Eng. https://doi.org/10.2118/173640-MS
Grosso AD, Bergmeister K, Inaudi D, Santa U (2001) Monitoring of bridges and concrete structures with fibre optic sensors in Europe, In: IABSE Symposium Report. International Association for Bridge and Structural Engineering, Vol. 84(6), pp 15-22

Inaudi D, Glisic B (2010) Long-range pipeline monitoring by distributed fibre optic sensing. J Press Vessel Technol. 132:011701. https ://doi.org/10.1115/1.3062942

Ingersoll LR, Zobel OJ, Ingersoll AC (1954) Heat conduction with engineering, geological and other applications. Madison University of Wisconsin Press, Madison

Kelvin TW (1882) Mathematical and Physical papers. II, p41, ff

Krause S, Taylor SL, Weatherill J, Haffenden A, Levy A, Cassidy NJ, Thomas PA (2012) Fibre-optic distributed temperature sensing for characterizing the impacts of vegetation coverage on thermal patterns in woodlands. Ecohydrology 6(5):754-764. https://doi. org/10.1002/eco.1296

Lau K-T (2003) Fibre-optic sensors and smart composites for concrete applications. Mag Concr Res 55(1):19-34. https://doi. org/10.1680/macr.2003.55.1.19

Lin Y-B, Chen J-C, Chang K-C, Chern J-C, Lai J-S (2005) Real-time monitoring of local scour by using fiber Bragg grating sensors. Smart Mater Struct 14(4):664. http://stacks.iop.org/0964-1726/14/ $\mathrm{i}=4 / \mathrm{a}=025$

Meininger TOD, Selker JS (2015) Bed conduction impact on fiber optic distributed temperature sensing water temperature measurements. Geosci Instrum Methods Data Syst 4:19.1-19.02. https://doi. org/10.5194/gi-4-19-2015 
Mogensen P (1983) Fluid to duct wall heat transfer in duct system heat storages. In: Proceedings of the International Conference on Subsurface Heat Storage in Theory and Practice, 6-8 June 1983, Stockholm, Sweden,pp 652-657

Ouyang Y, Hird R, Bolton MD (2017) The use of fibre optic distributed technology to detect changes in the sediment overburden. J Underw Technol 34(2):63-74. https://doi.org/10.3723/ut.34.06

Pilgrim J, Catmull S, Chippendale R, Tyreman R, Lewin P (2013) Offshore wind farm export cable current rating optimisation. In: Offshore 2013. November, Frankfurt, Germany, 1-10, pp 19-21

Raymond J, Robert G, Therrien R, Gosselin L (2010) A novel thermal response test using heating cables. In: Proceedings of the World geothermal congress, Bali, Indonesia (pp. 1-8)

Rui Y, Soga K (2018) Thermo-hydro-mechanical coupling analysis of a thermal pile. In: Proceedings of the Institution of Civil EngineersGeotechnical Engineering, pp, 1-19. https://doi.org/10.1680/jgeen .16 .00133

Rui Y, Kechavarzi C, O’Leary F, Barker C, Nicholson D, Soga K (2017) Integrity testing of pile cover using distributed fibre optic sensing. Sensors 17(12):2949. https://doi.org/10.3390/s17122949

Sebok E, Duque C, Engesgaard P, Boegh E (2015) Application of distributed temperature sensing for coupled mapping of sedimentation processes and spatio-temporal variability of groundwater discharge in soft-bedded streams. Hydrol Process 29:3408-3422. https://doi.org/10.1002/hyp.10455

Sebok E, Engesgaard P, Duque C (2017) Long-term monitoring of streambed sedimentation and scour in a dynamic stream based on seabed temperature time series. Environ Monit Assess 189:469. https://doi.org/10.1007/s10661-017-6194-x

Spruit R, van Tol F, Broere W, Doornenbal P, Hopman V (2017) Distributed temperature sensing applied during diaphragm wall construction. Can Geotech J 54(2):219-233. https://doi.org/10.1139/ cgj-2014-0522

Steele-Dunne SC, Rutten MM, Krzeminska DM, Hausner M, Tyler SW, Selker J, Bogaard TA, van de Giesen NC (2010) Feasibility of soil moisture estimation using passive distributed temperature sensing. Water Resour Res 46(W03534):1-12. https://doi. org/10.1029/2009WR008272

Woodside W, Messmer JH (1961) Thermal conductivity of porous media. I. Unconsolidated sands. J Appl Phys 32:1688-1699. https ://doi.org/10.1063/1.1728419

Zhao XF, Li L, Ba Q, Ou JP (2012) Scour monitoring system of subsea pipeline using distributed Brillouin optical sensors based on active thermometry. Opt Laser Technol 44:2125-2129 